\title{
Spatial and Temporal Distribution of Cancer Mortality in a Federative Unit of the Brazilian Legal Amazon Between 2000 and 2015
}

Mário Ribeiro Alves ( $\square$ malvesgeo@gmail.com )

Universidade Federal de Mato Grosso https://orcid.org/0000-0003-3665-6821

Jânia Cristina de Souza Oliveira

Universidade Federal de Mato Grosso

Amanda Cristina de Souza Andrade

Universidade Federal de Mato Grosso

Bárbara da Silva Nalin de Souza

Universidade Federal de Mato Grosso

Elicléia Filgueira Santiago de Azevedo

Universidade Federal de Mato Grosso

Rita Adriana Gomes de Souza

Universidade Federal de Mato Grosso

Noemi Dreyer Galvão

Universidade Federal de Mato Grosso

Research article

Keywords: Neoplasia, Information systems, Mortality Records, Spatial Analysis, Temporal Distribution

Posted Date: May 7th, 2020

DOI: https://doi.org/10.21203/rs.3.rs-26411/v1

License: (9) (i) This work is licensed under a Creative Commons Attribution 4.0 International License.

Read Full License 


\section{Abstract}

Background: About 41 million deaths were due to chronic noncommunicable diseases and of these, 9 million (22\%) had cancer as a basic cause of death. In Brazil, 2,023,038 deaths from cancer occurred between 1996 and 2010.

Methods: Ecological design study, in which mortality from neoplasia was analyzed, from 2000 to 2015, for the municipalities of the Mato Grosso state. Mortality rates due to cancer were calculated by the ratio of the sum of deaths by cancer in each quadrennium, divided by the average of the population in the two central years of the period, multiplied by 10,000 inhabitants. An annual percentage change was calculated by the ratio of the linear regression coefficient to the cancer mortality rates in the Mato Grosso state at the beginning of the analyzed period (2000 to 2003). Thematic maps were constructed for each quadrennium using intervals of equal classes.

Results: Cancer caused 31,097 deaths in the Mato Grosso state in the period, 13,058 in women and 18,039 in men, with a male to female ratio of 1.38. The top five causes of cancer death in the period were lung $(12.2 \%)$, prostate $(8.7 \%)$, stomach $(7.7 \%)$, breast $(6.0 \%)$ and liver $(4.7 \%)$. There is an increase in the number of municipalities with rates greater than 23.67 deaths per 100,000 inhabitants in the period.

Conclusion: The description of cancer mortality can bring important contributions to epidemiological studies. These studies are necessary, especially in Mato Grosso, since studies on this topic are scarce, and can potentially contribute to the identification of priority regions for intervention aiming to reduce mortality rates.

\section{Introduction}

Chronic noncommunicable diseases are responsible for most deaths worldwide. It is estimated that cancer is at the top of the basic causes of death and is the most important barrier to increasing life expectancy in the world [1].

In 2016, about 41 million deaths were due to chronic noncommunicable diseases and of these, 9 million (22\%) had cancer as a basic cause [1]. Worldwide, projections for the year 2030 indicate the occurrence of 26 million new cases and 17 million deaths from the disease [2]. These numbers express the importance of cancer as a leading cause of death worldwide [3].

In Brazil, between 1996 and 2010, 2,023,038 deaths from cancer occurred, with 53.9\% affecting men and $46.1 \%$ women [4]. In the year 2017, the five primary locations with the highest death rates in the male population in the country were: bronchi and lung with 15.60 per 100,000 , followed by prostate with 14.24 per 100,000 , thirdly the stomach with 8.82 per 100,000 , in fourth the esophagus with 6.41 per 100.000 and in fifth place the liver and biliary tract with 5.71 per 100.000. In the female population, for the same year, the primary location that showed the highest rate was the breast with 13.22 per 100,000 , secondly that of the bronchi and lung with 9.20 per 100,000, followed by cervical cancer with 5.14 per 100,000, in 
the fourth place the colon with 4.62 per 100,000 and in the fifth place the pancreas with 4.06 per 100,000 [5].

The estimate of new cases of cancer for the period 2020 to 2022 is 625 thousand and a crude rate of 252.04 per 100,000 for men and 217.31 per 100,000 for women, for the state of Mato Grosso [6].

Spatial analysis of data allows the analysis of cases according to the distribution in a specific geographical area. However, it is worth mentioning that the spaces are not homogeneous, because the spatial differentiation implies several other singularities, such as culture, education, income, genetic and housing characteristics [7].

In this way, the relevance of this study is unique, since the environment has characteristics that can act as risk factors for the occurrence of cancer. In addition, scientific production on the theme of cancer, using geoprocessing as an analysis tool, is still little explored, which further highlights the importance of this study, aiming to analyze the spatial distribution of the four-year rates of mortality from neoplasia, in the period from 2000 to 2015 .

\section{Methods}

Ecological design study, in which mortality from neoplasia (by municipality of residence) was analyzed, from 2000 to 2015, for the state of Mato Grosso.

Data on the estimated population of the state were acquired from IBGE (Institute of Geography and Statistics, in portuguese)[8] for the year 2018 (3,441,998 inhabitants, with a population density of 3.36 inhabitants per $\mathrm{km} 2$ and a territorial area of $\left.903,206,997 \mathrm{~km}^{2}\right)$. The Mato Grosso state is divided into 7 geographic regions and 141 municipalities (Figure 1).

Mortality data were obtained from the databases of the Mortality Information System (SIM, in portuguese)[9] provided by the Mato Grosso State Department of Health. Cancer deaths were analyzed under codes $\mathrm{COO}$ to C97, according to the 10th International Classification of Diseases (ICD-10). These deaths refer to individuals of all ages. Population estimates by age group were collected from the website of the Department of Informatics of the Unified Health System, the Brazilian public health system[10].

Mortality rates due to cancer were calculated by the ratio of the sum of deaths by cancer in each quadrennium, divided by the average of the population in the two central years of the period, multiplied by 10,000 inhabitants. The rates were adjusted by the direct method by age groups, with intervals of four years, considering as a standard population the distribution of the world population[11]. In order to reduce instability in the analysis of data on mortality by municipality, we sought to smooth out random fluctuations by grouping rates in four-year periods: 2000 to 2003; 2004 to $2007 ; 2008$ to $2011 ; 2012$ to 2015.

An annual percentage change was calculated by the ratio of the linear regression coefficient to the cancer mortality rates in the Mato Grosso state at the beginning of the analyzed period (2000 to 2003). Adopt a 
$5 \%$ significance level.

To explore the spatial distribution of cancer mortality rates, thematic maps were constructed for each quadrennium using intervals of equal classes (0.00; between 0.01 and 12.52; between 12.53 and 23.67; between 23.68 and 36.21 ; between 36.22 and 48.00; above 48.00). The intervals were defined from the distribution of rates in the first quadrennium (2000-2003). The geographical unit of analysis were the 141 municipalities of Mato Grosso. The municipalities of Itanhangá and Ipiranga do Norte were created in 2005, which made it impossible to calculate the mortality rate for the quadrennium from 2000 to 2003 and were declared as missings. The cartographic bases were obtained from the Brazilian Institute of Geography and Statistics[12]. The Kernel maps were built with an adaptive radius. Nine strata were used, divided into equal intervals.

For data analysis, the software STATA version 12.0 and the ArcMap Program version 10.3 were used. The study was approved by the Ethics and Research Committee of Júlio Muller Universitary Hospital (protocol 3.048.183).

\section{Results}

In the period from 2000 to 2015, cancer caused 31,097 deaths in the Mato Grosso state, 13,058 in women and 18,039 in men, with a male to female ratio of 1.38. The top five causes of cancer death in the period were lung $(12.2 \%)$, prostate $(8.7 \%)$, stomach $(7.7 \%)$, breast $(6.0 \%)$ and liver $(4.7 \%)$. The mortality rate in the state in the quadrenniums from 2000 to 2003, 2004 to 2007, 2008 to 2011 and 2012 to 2015 was $30.0,32.4,32.8$ and 33.2 per 100,000 inhabitants, respectively, indicating an average annual increase of $8.3 \%(p=0.030)$ (data not shown).

Figure 2 shows the proportion of municipalities according to the intervals of equal classes defined in the maps. There is an increase in the proportion of municipalities with mortality rates between 23.68 to 36.21 , between 36.22 to 48.00 and above 48.00 . For the remaining intervals ( 0.00 ; between 0.01 and 12.52; between 12.53 to 23.67 ), there was a downward trend.

Figure 3 shows the four-year trends in cancer mortality rates according to municipality. There is increase in the number of municipalities with rates greater than 23.67 deaths per 100,000 inhabitants in the period. The regions with the highest rate in the quadrenniums were West, Center-South, Southeast, CenterNorth and North, while the Northeast and Northwest regions had the lowest rates.

The kernel intensity map (Figure 4) confirms that the highest density of cancer mortality occurred in the West, Center-South, Southeast and Center-North regions of the state and the lowest in the Northeast and Northwest regions. This pattern tends to be maintained throughout the quadrenniums. For the North and Northwest regions there is a decrease in mortality densities over the four-year period. The Northeast region had the lowest densities in the entire period studied.

\section{Discussion}


The results of this study identified space and time patterns that point to an increase in standardized rates of cancer mortality in the State of Mato Grosso from 2000 to 2015.

According to IBGE data on the age distribution of the population, at least $80 \%$ of the state population is concentrated below 50 years of age. However, according to the Mato Grosso Oncology Care Action Plan, even though the state has a predominantly younger population, cancer has appeared as the second cause of death in mortality statistics (excluding external causes). In addition, there was also an increase in proportional cancer mortality, from $10.8 \%$ in 2001 to $14.3 \%$ in 2013[13].

The pattern shown in the state was different from the national pattern, where general rates for the disease have been showing some stability[6]. A study that described the main groups of causes of death from chronic non-communicable diseases between 1990 and 2015 according to estimates from the Global Burden of Disease (GBD) 2015 study, showed that, for Brazil, the standardized mortality rates for cancer went from 142.7 per 100,000 inhabitants (1990) to 133.5 per 100,000 inhabitants (2015), considered stable for the analyzed period[14].

The five main causes of death from cancer in the period for the state, considering the anatomical location, were lung, prostate, stomach, breast and liver. With the exception of liver cancer, which appears only in Mato Grosso, the others are also among the five main types of cancer that kill the most in Brazil, although not in the same order[15].

Estimates from Global Cancer Observatory show that, worldwide, lung cancer remains the leading cause of cancer mortality, with 1.8 million deaths predicted in 2018, representing about 1 in 5 cancer deaths. Prostate cancer is considered the fifth leading cause of cancer death in men, and breast cancer the first in women, accounting for about 1 in 4 cancer cases in this group. Stomach cancer remains an important cancer worldwide, accounting for about 783,000 deaths, equivalent to 1 in 12 deaths from cancer, while liver cancer is considered the fourth leading cause of cancer death worldwide[3].

The profile of deaths presented in the state has been associated with more urbanized, industrialized regions with an aging population, in line with developed countries in the West. On the other hand, the state continues to live with deaths due to types of cancer associated with infections, such as stomach cancer, which have a high potential for prevention and tend to be more prevalent in countries of low and medium development[6].

Cancer is a multifactorial disease, however, according to the World Health Organization (WHO), some risk factors are related to most deaths from chronic noncommunicable diseases, including cancer, having an important contribution to the burden of diseases. Among these factors, smoking, excessive alcohol consumption, inadequate diet and physical inactivity stand out[16].

Data from the National Health Survey for Mato Grosso[17], showed that only $37.0 \%$ of the state's population aged 18 or over reported recommended consumption of fruits and vegetables, while $52.9 \%$ 
were classified as insufficiently active (behind Rondônia state only), $24.3 \%$ reported weekly alcohol consumption and $12.8 \%$ as current users of tobacco products.

There was also a higher proportion of deaths for men. This can be explained by the fact that the three main types of cancer were more present in this group. A study that aimed to analyze the temporal trend of cancer mortality in Brazil in the period from 1996 to 2010, in addition to calculating the projection of mortality for the period from 2011 to 2030 , showed that $53.9 \%$ of deaths affected men and $46.1 \%$ were female. In addition, there was stability in female mortality and a significant increase in the trend for males between 1996 and 2008[6].

Literature data have pointed out that men and women have different life expectancies and habits, with greater female demand for health services and, consequently, with women adopting greater preventive health care than men[18].

Spatial analysis of cancer mortality, through the use of maps, is an important tool to evaluate health risks, especially when this type of analysis considers environmental aspects, as the visualization of information allows a better understanding of how relationships occur, and can contribute to the identification of priority territories, as well as a better understanding of the health-disease process and health planning actions[19].

The use of geoprocessing also allows for a historical analysis of the demand for care in health services, helping to optimize care in health units and producing important changes in epidemiological and operational indicators[20].

The use of this analysis allowed us to identify that the regions of the state that had the highest mortality rates were the West, Center-South, Southeast, Center-North and North regions. These regions showed differences that can be expressed through socioeconomic indicators of the municipalities that integrate them, with also an inequality in installed capacity and in public and private investments, especially in those with less economic dynamism[21]. Despite this diversity, what can be observed is that, in general, these regions have less availability of primary care services, and some also have low health care expenditures (West Region), low availability of specialized assistance establishments (West and North Regions) and low outpatient care per inhabitant in medium and high complexity (West, North and CenterNorth Regions)[22,23].

Specifically with regard to primary health care services, they serve as a gateway to the health care network. The low availability of these services may impair the identification, in the initial phase, of the first lesions suggestive of cancer and, consequently, determine the specialized services as the predominant places for the diagnosis of the disease, since the confirmation of the lesions requires procedures and supplies available only in medium and high complexity services[24].

Another characteristic of the state is that, with the exception of some municipalities in the Center-South region, agriculture and services are the economic base of practically all regions of the same[22]. 
Currently, Mato Grosso is the state that most produces soy, corn, cotton and cattle in Brazil, having become, for several years, a strategic territory for the expansion of agribusiness[25], in whose model predominates large monoculture properties, intensive use of chemical and pesticide fertilizers to control unwanted species and use of biotechnology (transgenics)[26]. This issue was evidenced by the higher cancer mortality rates in cities close to BR-163 (a federal highway) (Figure 3), which can probably be explained by the relationship between soy production (with transgenics and use of pesticides, which have highly carcinogenic potentials) and the presence of the highway to transport production to other countries[27].

The state has some municipalities that concentrate a large part of the national agricultural production, such as some municipalities located in the central and southeast regions. Consequently, due to the chemical-dependent production method, in these municipalities there are high rates of consumption of pesticides[28].

The relationship between exposure to pesticides and cancer development has been established in several studies[29,30,31,32], being modulated by type of product used, time of exposure and amount absorbed by the body[33]. It is important to highlight that the entire population is susceptible to multiple exposures to pesticides, through the consumption of contaminated water and food, and not only farmers and workers in the pesticide production chain[34].

A possible limitation of the study concerns the incorrect or incomplete filling of information on death certificates in relation to the causes. There was no correction of rates for deaths from ill-defined causes. However, deaths from these causes have decreased in recent decades in all Brazilian regions, especially in cities outside the capitals[35,36]. This has indicated an improvement in the quality of the information recorded in the Mortality Information System, especially for the group of malignant neoplasms, where the quality of information about the basic cause registered in the system can be considered better than for other groups of causes[37].

In 2015, the UN adopted a set of 17 goals as part of a sustainable development agenda. One of the goals is related to the reduction of premature mortality due to noncommunicable diseases through prevention and treatment. It has therefore become a global priority to monitor trends in mortality due to these diseases, provided by quality information systems, in order to verify whether national and global commitments are being achieved[38].

Thus, the description of cancer mortality can bring important contributions to epidemiological studies based on the person-space-time triad. Studies of this magnitude are necessary, especially in Mato Grosso, since studies on this topic are scarce, and knowing this reality can potentially contribute to the identification of priority regions for intervention aiming to reduce mortality rates.

\section{Abbreviations}


IBGE: Instituto Brasileiro de Geografia e Estatística; SIM: Sistema de Informação sobre Mortalidade; ICD10: International Classification of Diseases; GBD: Global Burden of Disease; WHO: World Health Organization.

\section{Declaration}

\section{Acknowledgements}

To the Institute of Collective Health of the Mato Grosso Federal University, for the opportunity of work and learning. To funders, for the support needed for this work.

\section{Author's contributions}

NDG and BSNS designed the study; MRA and ACSA analyzed the data; JCSO did literature search; EFSA drafted the manuscript; RAGS revised the manuscript. All authors revised and approved the submitted manuscript.

\section{Funding}

This work was supported by the State Health Department of Mato Grosso and Public Ministry of Labor (Twenty-third Region). Both were not involved in the study design or in the writing of the manuscript.

\section{Availability of data and materials}

The data used in this study were authorized by the State Health Department of Mato Grosso and, therefore, are not available to the public.

\section{Ethics approval and consent to participate}

The study was approved by the Ethics and Research Committee of Júlio Muller Universitary Hospital (CAAE: 98150718.1.40.8124), with ethical approval obtained for mortality data from the referred hospital.

\section{Consent of publication}

The study involves anonymous mortality data, which is not identifiable.

\section{Competing interests}

The authors declare that they have no competing interests.

\section{References}

1. World Health Organization. Global Health Observatory. Geneva: World Health Organization; 2018. who.int/gho/database/en/. 
2. Thun MJ, DeLancey JO, Center MM, et al. The global burden of cancer: priorities for prevention. Carcinogenesis. 2010; 31:100-110.

3. Bray F, Ferlay J, Soerjomataram I, Siegel RL, Torre LA, Jemal A. Global cancer statistics 2018 : GLOBOCAN estimates of incidence and mortality worldwide for 36 cancers in 185 countries. CA Cancer J Clin. 2018 Nov;68(6):394-424.

4. Barbosa IR, Souza DLB, Bernal MM, Costa ICC. Cancer mortality in Brazil: Temporal Trends and Predictions for the Year 2030. Medicine (Baltimore) 2015; Volume 94, Number 16: e746.

5. Instituto Nacional de Câncer (BR). Atlas da Mortalidade. http://mortalidade.inca.gov.br/Mortalidade/. Accessed 15 Feb 2020.

6. Instituto Nacional de Câncer José Alencar Gomes da Silva. Estimativa 2020: incidência de câncer no Brasil. Rio de Janeiro: INCA, 2019. 120 p.

7. Barcellos C, Bastos Fl. Geoprocessamento, ambiente e saúde: uma união possível? Cad Saúde Pública 1996; 12: 389-97.

8. Instituto Brasileiro de Geografia e Estatística. IBGE. http://www.ibge.gov.br. Accessed 10 Jul 2018.

9. Sistema de Informação sobre Mortalidade (SIM). Ministério da Saúde. http://www2.datasus.gov.br/. Accessed 10 0Jul 2018.

10. Estimativas populacionais. Ministério da Saúde. http://datasus.saude.gov.br/populacao-residente/. Accessed 10 Jul 2018.

11. Doll R. Comparison between registries and age-standardized rates. In: Waterhouse JA, Muir CS, Correa P, Powell J, editors. Cancer incidence in five continents. Lyon: IARC.1976; 3: 453-9.

12. Instituto Brasileiro de Geografia e Estatística. IBGE. https://mapas.ibge.gov.br/bases-ereferencial/bases-cartograficas/malhas-digitais. Accessed 10 Jul 2018.

13. Secretaria de Estado de Saúde (SES-MT). Governo de Mato Grosso. Plano de Ação da Atenção Oncológica no Estado de Mato Grosso 2017 a 2019. Cuiabá: SES-MT, 2017.

14. Malta DC, França E, Abreu DMX, Perillo RD, Salmen MC, Teixeira RA, Passos V, Souza MFM, Mooney M, Naghavi M. Mortality due to noncommunicable diseases in Brazil, 1990 to 2015, according to estimates from the Global Burden of Disease study. Sao Paulo Med J. 2017;135(3):213-21.

15. Ministério da Saúde (MS). Instituto Nacional de Câncer. Coordenação de Prevenção e Vigilância. Divisão de Vigilância e Análise de Situação, 2019.

16. World Health Organization (WHO). Global status report on noncommunicable diseases 2010. Geneva: WHO, 2011.

17. Ministério da Saúde (MS). Pesquisa Nacional de Saúde 2013. Percepção do estado de saúde, estilos de vida e doenças crônicas. Brasil, Grandes Regiões e Unidades da Federação. Rio de Janeiro: MS, 2014.

18. Vieira KLD, Gomes VLO, Borba MR, Costa CFS. Atendimento da população masculina em unidade básica saúde da família: motivos para a (não) procura.Esc. Anna Nery, Rio de Janeiro, v. 17, n. 1, p. 120-127, mar. 2013. 
19. Carvalho MS, Souza-Santos R. Análise de dados espaciais em saúde pública: métodos, problemas, perspectivas. Cad. SaúdePública 2005; v. 21, n. 2, p. 361-378.

20. Nardi SMT, Paschoal JAA, Pedro HSP, Paschoal VD, Sichieri EP. Geoprocessamento em Saúde Pública: fundamentos e aplicações. Revlnst Adolfo Lutz 2013; 72(3):185-91.

21. Secretaria de Estado de Saúde do Estado de Mato Grosso (SES-MT). Escola de Saúde Pública do Estado de Mato Grosso. Plano Estadual de Educação Permanente do Mato Grosso - PEEPS/MT. Cuiabá: SES-MT, 2019.

22. Scatena JHG, Oliveira LR, Galvão ND, das Neves MAB. Caracterização das regiões de saúde de Mato Grosso. In: Regiões de Saúde: diversidade e processo de regionalização em Mato Grosso. Organizadores: Scatena JHG, Kehrig RT, Spinelli MAS. 1ª. Ed. São Paulo: Hucitec, 2014a.

23. Scatena JHG, Oliveira LR, Galvão ND, das Neves MAB. O uso de indicadores compostos para classificação das regiões de saúde de Mato Grosso. In: Regiões de Saúde: diversidade e processo de regionalização em Mato Grosso. Organizadores: Scatena JHG, Kehrig RT, Spinelli MAS. $1^{\text {a }}$. Ed. São Paulo: Hucitec, 2014b.

24. Aquino RCA, Lima MLLT, Silva VL, Alencar FL, Rodrigues M. Acesso e itinerário terapêutico aos serviços de saúde nos casos de óbitos por câncer de boca. Rev. CEFAC. 2018; 20(5): 595-603.

25. Instituto Brasileiro de Geografia e Estatística (IBGE). Produção Agrícola Municipal 2015. Brasília: IBGE, 2015. https://sidra.ibge.gov.br/pesquisa/pam/tabelas. Accessed 20 Jul 2019.

26. Albergoni L, Pelaez V. Da Revolução Verde à agrobiotecnologia: ruptura ou continuidade de paradigmas? Rev de Economia. 2007; 33(1): 31-5.

27. Departamento Nacional de Infraestrutura de Transportes. Ministério da Infraestrutura. http://www.dnit.gov.br/noticias/governo-federal-conclui-asfaltamento-da-br-163-pa. Accessed $20 \mathrm{Apr}$ 2020.

28. Beserra L. Agrotóxicos, vulnerabilidade socioambientais e saúde: uma avaliação participativa em municípios da bacia do rio Juruena, Mato Grosso. UFMT: 2017. 137 f.

29. Barry KH, Koutros S, Lubin JH, Coble JB, Barone-Adesi F, Beane Freeman LE, et al. Methyl bromide exposure and cancer risk in the Agricultural Health Study. Cancer Causes Control 2012; 23:807-818.

30. VoPham T, Brooks MM, Yuan JM, Talbott EO, Ruddell D, Hart JE, et al. Pesticide exposure and hepatocellular carcinoma risk: a case-control study using a geographic information system (GIS) to link SEER-Medicare and California pesticide data. Environ Res 2015; 143:68-82.

31. Koutros S, Beane Freeman LE, Lubin JH, Heltshe SL, Andreotti G, Barry KH, et al. Risk of total and aggressive prostate cancer and pesticide use in the Agricultural Health Study. Am J Epidemiol 2013; 177:59-74.

32. Parada H Jr, Wolff MS, Engel LS, White AJ, Eng SM, Cleveland RJ, et al. Organochlorine insecticides DDT and chlordane in relation to survival following breast cancer. Int J Cancer 2016; 138:565-575.

33. Alavanja MCR, Hoppin JÁ, Kamel F. Health effects of chronic pesticide exposure: cancer and neurotoxity. Annu. Rev. Public Health 2004; 25:157-197. 
34. Dutra LS, Ferreira AP. Associação entre malformações congênitas e a utilização de agrotóxicos em monoculturas no Paraná, Brasil. Saúde debate 41 (spe2) Jun 2017.

35. Silva GA, Gamarra CJ, Girianelli VR, Valente JG. Tendência da mortalidade por câncer nas capitais e interior do Brasil entre 1980 e 2006. Rev Saúde Pública 2011;45(6):1009-18.

36. Frias PG, Szwarcwald CL, Lira PIC. Avaliação dos sistemas de informações sobre nascidos vivos e óbitos no Brasil na década de 2000. Cadernos de Saúde Pública 2014; 30(10), 2068-2280.

37. Mello Jorge MH, Gotlieb SLD, Laurenti R. 0 sistema de informações sobre mortalidade: problemas e propostas para o seu enfrentamento I-mortes por causas naturais. RevBrasEpidemiol. 2002;5(2):197211.

38. United Nations (UN). Economic and Social Council. Nova lorque: United Nations; 2019. https://undocs.org/E/2019/68. Accessed 28 Jan 2020.

\section{Figures}




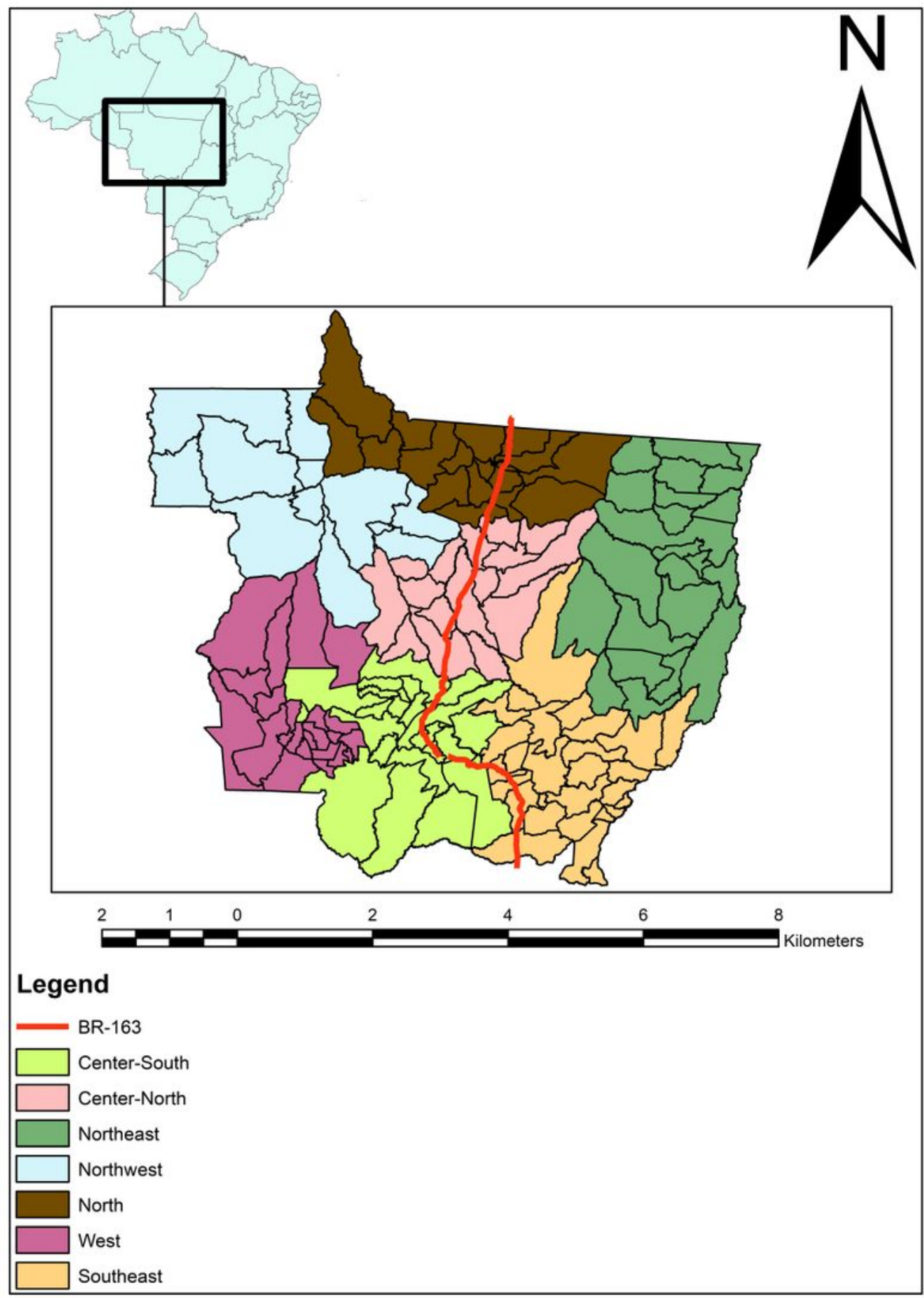

Figure 1

Location and regional division of Mato Grosso state, Brazil. 


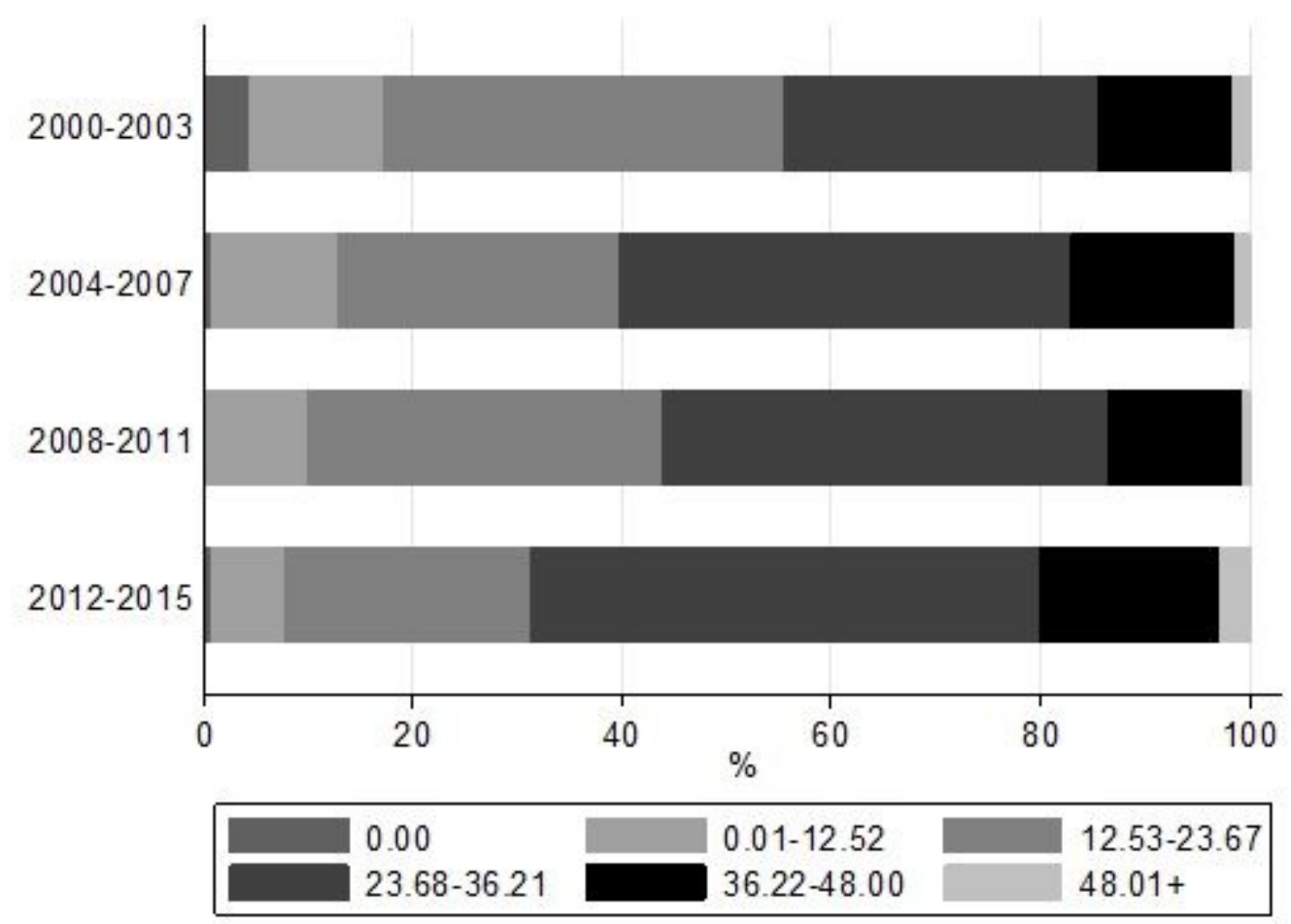

Figure 2

Proportions of cancer mortality rates in the municipalities of Mato Grosso state (2000-2015). 


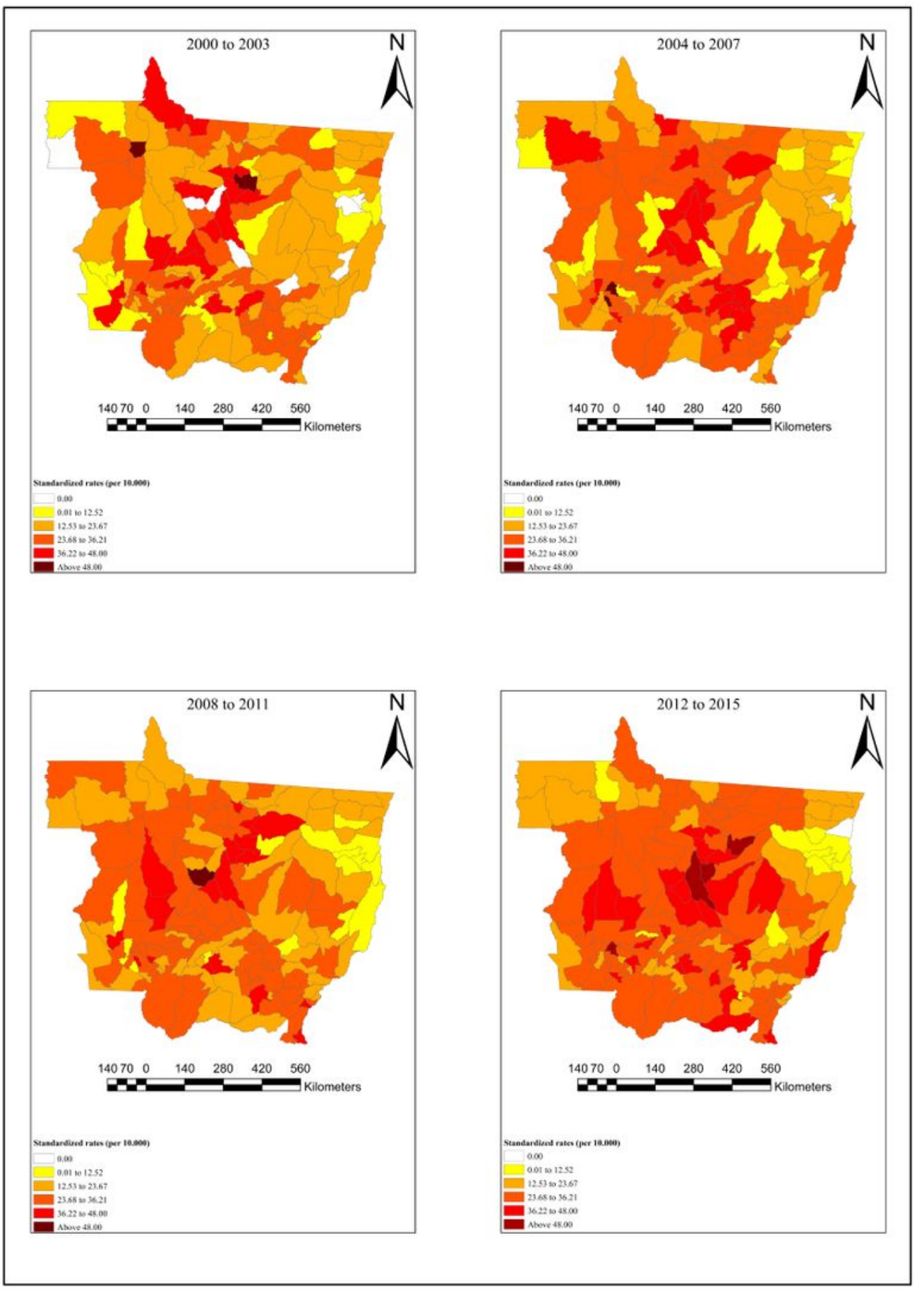

Figure 3

Cancer mortality rates in the municipalities of Mato Grosso state (2000-2015). 


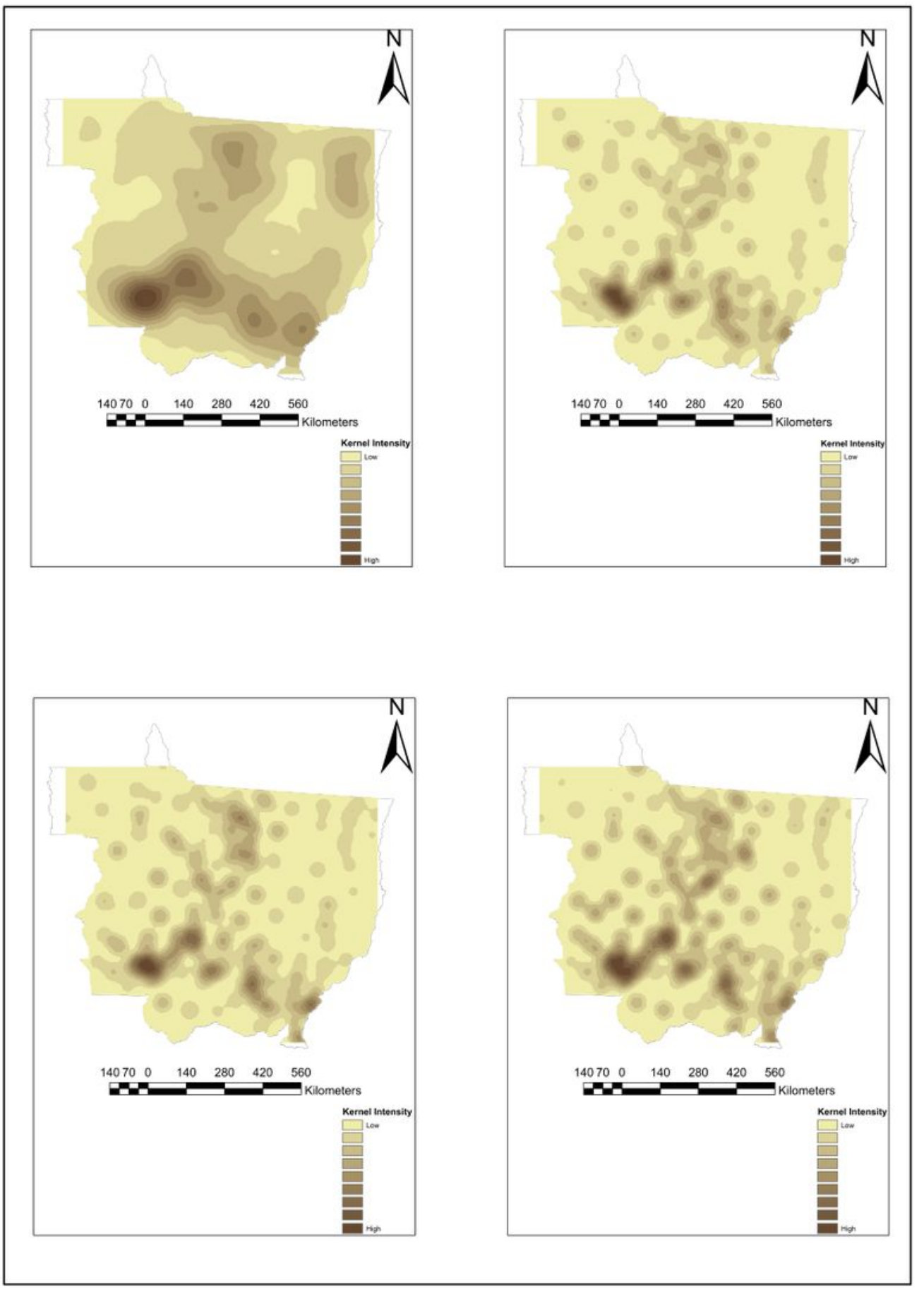

Figure 4

Kernel intensity of cancer mortality densities (2000 to 2015). 